\title{
DEMOGRAPHIC FORECASTS AND VOLATILITY OF INVESTMENT RATES VS. LABOR PRODUCTIVITY TRAJECTORIES
}

\author{
Monika BOLIŃSKA (D) ${ }^{1}$, Paweł DYKAS (D) ${ }^{1}$, Grzegorz MENTEL (D)2*, \\ Tomasz MISIAK (D) 3 \\ ${ }^{1}$ Department of Mathematical Economics, Faculty of Management and Social Communication, \\ Jagiellonian University in Cracow, Cracow, Poland \\ ${ }^{2}$ Department of Quantitative Methods, The Faculty of Management, \\ Rzeszow University of Technology, Rzeszow, Poland \\ ${ }^{3}$ Department of Economics, The Faculty of Management, \\ Rzeszow University of Technology, Rzeszow, Poland
}

Received 14 December 2018; accepted 29 April 2019

\begin{abstract}
In the article the authors attempted to develop the neoclassical model of economic growth, repealing two assumptions regarding the Solow growth model. First of all, the authors assume that the growth path of the number of employees is increasing asymptotically to a fixed value, not to infinity as in the Solow model. The growth paths of the number of employees were determined based on demographic forecasts and the economic activity coefficient, which in the paper is understood as the ratio of the number of employees to the number of people. Secondly, the authors repeal the assumption of a fixed investment rate by taking into account the trend of changes in investment rates (a growing or declining trend). The theoretical model obtained was subjected to calibration and then numerical simulations were carried out. It was assumed that investment rates in the Polish economy decrease (from 25 to $15 \%$ ) or grow (from 15 to 25\%). Numerical simulations were based on demographic forecasts for the Polish economy up to 2050. Moreover, two scenarios for shaping the economic activity coefficient were considered: realistic one when in the period 2000-2050 it increased from 0.38 to 0.5 . In the second scenario, it was optimistic that the increase would be $50 \%$ higher than in the first option and in 2050 it would reach 0.56. Important conclusions from the study can be presented as follows: (i) the population decline can be offset by the growing economic activity rate and therefore does not have a negative impact on economic growth, (ii) the negative impact of demographic changes on economic growth can also be offset by growing investment rates.
\end{abstract}

Keywords: economic growth, demographic forecasts, labor productivity, technical devices, numerical simulations, population forecasting, trends in investment rates.

JEL Classification: C63, E22, J11, J20, O40.

*Corresponding author. E-mail: gmentel@prz.edu.pl 


\section{Introduction}

In the literature on the subject the role of demographic factors has been rising for many years. However, many economists forget about an impact of demographic processes on an economic growth. This may have resulted from the fact that several post-war decades did not generate negative demographic problems and various cross-sectional studies indicated a negligible, often negative impact of population growth on a production growth. In the 90s of the previous century Barro $(1991,1997)$ introduced several demographic variables to study the processes of real convergence of economies. According to the results of Barro's research a demographic increase and mortality generated a negative impact on the production volume, and a population size and population density had a positive influence on the production volume. In most subsequent surveys the attention is paid not only to the issues of population change, but primarily to the structure of the population of the studied economies and other variables that define the demographic processes.

Investments are also an important factor that influences on the economic growth. Investment rates are macroeconomic variables that are very sensitive to economic fluctuations. The analysis of the trajectory of changes in the investment rates of the Polish economy in 1990-2017 was confirmed by the fact that investments were subject to cyclical fluctuations with a certain tendency of a smoothed trend (growing or decreasing).

In the article the authors attempt to develop a neoclassical growth model by repealing two basic assumptions of the traditional Solow model. First of all, the authors assume that the growth path of the number of employees results from the interaction of population growth paths and the economic activity coefficient, which in the study is understood as the ratio of the number of employees to the number of people. While making an increase in the number of employees upon a population size, the authors take into account the demographic processes. In addition, the growth path of the number of employees adopted in the study increases asymptotically to a fixed value (resulting from forecasts), and not to infinity as it is for the Solow model. Secondly, the authors repeal the assumption of a fixed investment rate and take into account the trends of changes in investment rates (a growing or decreasing trend).

Therefore, the aim of the analyses carried out, both in theoretical and numerical simulations, was to bring the model closer to reality. The assumption about the stability of investment rates and the unlimited increase in the number of employees resulting from the growing population size are too sharp and deviate from real changes in the economy (fluctuations in investment rates or low or negative rates of demographic growth).

The main benefits that the authors want to achieve boil down to determining whether the growing economic activity rate and appropriate investment rates are able to offset the negative demographic forecasts regarding the size of the population in Poland by 2050, so that they do not adversely affect the economic growth.

Numerical simulations allowed determining product growth paths for the Polish economy as a unit of effective work with different scenarios regarding trends in changes in investment rates and various options for economic activity. In addition, a demographic forecast of population size in Poland until 2050 developed by the Central Statistical Office was used for numerical simulations. 
The structure of the presented study is as follows. The second point presents a review of the literature. The third point contains an analytical solution of the model that takes into account alternative assumptions regarding the shaping of the growth path of employees and trends of changes in investment rates. In the fourth point the parameters of the presented model were calibrated and numerical simulations of product growth paths per unit of effective work in the considered scenarios were presented. The fifth point summarizes the considerations and more important conclusions.

\section{Literature review}

An economic growth is a multidimensional process, it is a part of a mutually unequivocal relation between the size of the population, capital resources, investments or technical progress. It is a dynamic, long-term process that leads to an increase of production potential. Based on the literature on the subject, models of economic growth can be divided into the following groups: Keynesian economic models, neoclassical models, endogenous growth models, or real business cycle models (Dykas \& Misiak, 2016).

The contemporary theory of economic growth is mainly based on neoclassical models. In 1956 Solow published a model of economic growth which became the foundation for later neoclassical models of economic growth. The Solow economic growth model was based on the power production function of the Cobb-Douglas type and on the equation of capital accumulation, which determines its growth as investments in this capital less its depreciated value. This model also assumed a constant income from the scale of the production process, a constant rate of a technical progress, or a constant rate of an increase in the number of employees (Solow, 1956). The basic advantages of the Solow model include the form of the equation that describes the accumulation of tangible capital, an uncomplicated analytical form of the model solution, which, with the power production function, is easily empirically verifiable by determining the growth paths of technical labor or labor productivity. The main weaknesses of the model include the adoption of physical capital as the only factor of production, thus omitting, for instance, human capital, adopting permanent economies of scale and treating technical progress or the number of employees as exogenous variables. (for more on the disadvantages and critiques of the Solow model see, e.g., McCombie, 2000, 2001).

The criticism of the Solow model was mainly based on the issues of exogenous technical progress and the stability of savings rates. Naturally, the next stage in the evolution of the theory of growth was the rejection of the assumption of a constant rate of savings and the endogenisation of technical progress. The rate of savings has become endogenous, i.e. it was the subject of optimization allowing its change over time. This was done in two ways. The first in the framework of dynastic models, which in the 20s of the twentieth century initiated the F. P. Ramsey and in the 1960s D. Cass and T. C. Koopmans. The second approach is related to the works of P. A. Diamond and models called intergenerational. A special emphasis of many researchers attached to the endogenisation of technical progress. These ideas were developed as part of the new theory of growth where two main trends of research can be distinguished. The first approach emphasizes that the driving force behind growth is the accumulation of knowledge. In the second approach, it is assumed that capital accumulation is fundamental 
to growth. Capital is recognized more broadly, taking into account primarily human capital as a factor generating technical progress. According to the first approach in the endogenisation models of the accumulation of technological knowledge, technical progress is the result of work carried out in the research and development (R \& D) sector, which aims to create new knowledge. This approach can be found, for example, in the works of Romer (1990), Grossman and Helpman (1991), Baumol (1990), Aghion and Howitt (1992) or Jones (1995). In these models, the long-term product growth rate per employee is determined within the model and not by the exogenous rate of technical progress. An exogenous factor is the rate of population growth. The models also show that the rate of product growth per employee is a growing function of the population growth rate.

Capital accumulation models are the second trend of the new growth theory. These include, among others works by: Barro (1989), Lucas (1988), Romer (1986) or even Mankiw, Romer and Weil (1992). Capital is understood more broadly because in addition to physical capital it also includes human capital identified with the stock of knowledge, skills and vital forces contained in society. These models assume high product flexibility in relation to the basic production factors, which in turn allows explaining large international development differences. It is allowed to generate long-term growth without resorting to endogenous technical changes and changes in the population. In addition, some authors emphasize that human capital resources should be high enough for the economy to enter a higher level of growth. Moreover, with an increase of human capital, the number of population decreases, because human capital is more productive in the production of goods and additional human capital than the increase in population. Research based on human capital models therefore treats population growth as an endogenous variable. The population growth rate is negatively correlated with human capital resources. A higher stock of human capital reduces the demand for children, as it raises the alternative cost of time spent with them (see, for example, the Becker model, Murphy \& Tamura, 1990). A similar approach to the relationship between the human capital resource and the population size dominates in the Unified Growth Theory initiated by Oded Galor (2011). This theory is a special development of the theory of endogenous economic growth on the basis of which one can explain the transition from the era of Malthusian stagnation to the modern era of sustainable economic growth. The era of Malthusian stagnation was characterized by slow technical progress with a relatively fast rate of population growth. At the same time benefits of technological progress compensated by natural growth. In the modern era of sustainable economic growth, technological progress is no longer conducive to population growth but to the accumulation of human capital, which is beneficial to technical progress (Galor \& Weil, 2000).

In addition to models that take into account the endogenisation of technical access, some researchers attempted to repeal the real assumptions regarding the number of populations that determine the increase in the number of employees. Therefore, some models were created where the assumption about a constant growth rate of the number of employed persons is avoided, which takes into account demographic changes taking place in many countries. In the Solow model it is assumed that there is a constant rate of an increase in the number of employees, this determines the path of growth in the number of employees that is growing to infinity in the long run. The path of growth in the number of employees heading to 
infinity seems to be an unrealistic assumption. In addition, modern demographic processes that take place in many developed economies suggest that there may be a downward trend in the number of employees, which may be pessimistic demographic forecasts regarding the size of the population for Western European countries.

The Solow growth model allow conduction an indirect analysis of relations between a population growth and an economic growth (Barro \& Sala-i-Martin, 2004). The labor productivity function depends on the capital per employee, which in turn is determined by the investment rate, the rate of population growth, the rate of capital depreciation and the rate of technical progress. In the conditions of long-term equilibrium, when labor productivity is constant, total production grows at a rate of population growth. In this way, in the Solow model, an impact of demographic changes on economic growth can be theoretically considered, provided that the rate of employment growth is a constant percentage of the growing population.

Brida, Accinelli (2007), Ferrara, Guerrini (2009) and Guerrini (2010a) are considering a Ramsey economic growth model with an assumption that the population growth path is logistic. Similar analyzes were conducted based on the AK model (Bucci \& Guerrini, 2009) and Mankiwa-Romer-Weil (Guerrini, 2010b). An impact of the delayed population dynamics, along the logistical path of population growth, for the long-term sustainability of the Solow growth model can be found among others in the work of Bianca and Guerrini (2014). Prettner (2013) investigates the consequences of an aging population based on an endogenous model of knowledge accumulation with a separate R\&D sector as in Romer (1990). Consider two variants in the tide based on an endogenous model with scale effects and a semi-endogenous growth model without scale effects. Analytically, it shows that the increasing life longevity has a positive impact on the increase in per capita production, while the fertility decrease has a negative impact on the increase in per capita production. It also shows that the effect of life longevity dominates the effect of fertility in an endogenous model. In addition, population aging fosters long-run growth in endogenous growth models, while the converse holds true in semi-endogenous growth frameworks.

Repealing the assumption concerning fixed rates of an increase in the number of employees on the example of the Solow model can also be found in the work of Filipowicz, Syrek, and Tokarski (2017). In this article, the authors adopt two alternative trajectories of an increase in the number of employees than in the standard Solow model. In the first variant, the number of employees grows asymptotically to a certain constant along the logistics curve. In the second case, the authors consider the path of an increase in the number of working as a function of the density of the normal distribution. With the logistic path of growth in the number of employees, labor productivity and technical equipment of labor increase to an asymptote higher than in the original Solow model, while with the Gaussian growth path the labor productivity and technical work equipment grow to infinity.

In the context of the above literature analysis, it is also legitimate to consider whether the inclusion of negative demographic effects (e.g. a decline in the population) can be offset by an appropriate investment policy. To this end, the assumption about the stability of investment rates should also be repealed, taking into account their variability over time. This is a reference to rejecting the permanence of savings rates in optimistic dynastic or intergenerational models. 
In addition, in the theory of economics one can notice a persistent state of dichotomy between the theory of economic growth and the theory of economic fluctuations, which is one of the key dilemmas of a growth and development (Malaga, 2011). In the study by Dykas and Misiak (2016) the authors try to determine an impact of the interaction of changes in investment rates over time on an economic growth by repealing the assumption of the Solow model with a fixed investment rate. The authors assume that investments deviate from their average level, i.e. they are subject to cyclical fluctuations. Therefore, for the description of investments they introduce a sinusoidally dependent function from time. The analyzes carried out by the authors show that an introduction of interest rates sine-dependent investments in time affects significantly the cyclicality of technical work equipment and labor productivity (Kudinova \& Verba, 2014; Botrić, Božić, \& Broz, 2017).

In this article the authors attempt to analyze the work efficiency path assuming that the trajectory of the number of employees strives for a horizontal asymptot determined by the interactions between the population size forecast in 2050 and changes in the economic activity coefficient. In addition the authors assume a growing (from 15 to $25 \%$ ) and a declining trend (from 25 to 15\%) of investment rates thus repealing quite a sharp assumption of the traditional Solow model with a constant investment rate in the economy. Based on numerical simulations carried out for Poland, taking into account the population decline in the period 2000-2050, they will attempt to demonstrate whether the impact of population decline can be compensated by appropriate investment policy so that it does not adversely affect the trajectory of labor productivity growth.

\section{The model}

The economic growth model considered in the study is based on the following assumptions:

1) The product is given by the following power production function (more on the neoclassical production function can be found in the study Żółtowska (1997) or Romer (2001)):

$$
Y(t)=(K(t))^{\alpha}(E(t))^{1-\alpha}
$$

where $\alpha \in(0 ; 1)$, while $Y$ is a product produced in the economy, while $K, E$ - are (respectively) outlays on physical capital and the unit of effective work (which is the product of the number of employees and the resources of scientific and technical knowledge). In addition, $\alpha$ is the flexibility of the product created in the economy in relation to capital expenditure, and $1-\alpha$ it is the product's flexibility relative to the units of effective work ${ }^{1}$.

2) An increase in the capital stock at time $t$, as in the Solow model (Solow, 1956), equal to the difference between the product weighted by the investment rate and the material capital weighted by its depreciation rate, hence:

$$
\dot{K}(t)=s(t) Y(t)-\delta K(t)
$$

where $\delta \in(0 ; 1)$ is the rate of capital depreciation.

\footnotetext{
${ }^{1}$ All subsequent macroeconomic variables are assumed to be differentiable functions of time $t \geq 0$. The record $x(t)$ will mean the value of the variable $x$ at the moment $t$, and $\dot{x}(t)=d x / d t$ - the derivative of the variable $\mathrm{x}$ after the time $t$, i.e. (economically speaking) an increase in the value of this variable at the moment $t$.
} 
3) The investment rate is determined according to the following formula:

$$
s(t)=s_{0}+\eta e^{-v \cdot t}
$$

where $s_{0}, v>0$.

The investment rate described by the relation (3) is characterized by the fact that the investment rate is $s_{0}+\eta>0$ in the zero period. Moving from $t$ to infinity, we get, which means that the function (3) has a horizontal asymptote. Moreover:

$$
\operatorname{sgn}\left(s^{\prime}(t)\right)=\left\{\begin{array}{l}
1 \text { dla } \in\left(-s_{0} ; 0\right) \\
-1 \text { dla } \in(0 ; \infty)
\end{array},\right.
$$

We get $\eta<0(\eta>0)$, the investment growth path (3) increases (decreases) asymptotically to the value equal to $s_{0}>0$.

4) The number of employees $L(t)$ at the moment $t$ is defined by the following relations:

where $\tau, \theta, \lambda, \tau-\theta>0$.

$$
L(t)=\tau-\theta e^{-\lambda \cdot t}
$$

Similarly to the investment rate described in (3), the growth path of the number of employees has a horizontal asymptote $\tau>0$, which results from that $L(t) \rightarrow \tau(t \rightarrow \infty)$. In addition $L^{\prime}(t)=\lambda \theta e^{-\lambda t}>0$, therefore, the growth path of the number of employees is growing exponentially from the level $\tau-\theta>0$ to the value $\tau$.

5) Units of effective work $E(t)$ increase according to the rate of growth equal to $g+l(t)$, with $g>0$ being the rate of Harrodian technical progress, and $l(t)=\frac{\dot{L}(t)}{L(t)}$ is the rate of increase in the number of employees, which results from the fact that the growth rate of the number of employees can be written as:

$$
\dot{E}(t) / E(t)=g+l(t)
$$

Hence, and from the relation 3 ) it results that the rate of an increase in the number of employees is described by the following equation:

$$
l(t)=\frac{\theta \lambda e^{-\lambda \cdot t}}{\tau-\theta e^{-\lambda \cdot t}},
$$

6) In addition, assuming that $y_{E}=Y / E$ and $k_{E}=K /$ are (respectively) the stream of product produced and the capital stock per unit of effective work, while $y=Y / L$ and $k=K /$ are (respectively) work efficiency and technical arming work, one can get the relations:

$$
\begin{aligned}
& y(t)=A_{0} e^{g t} y_{E}(t) ; \\
& k(t)=A_{0} e^{g t} k_{E}(t) ; \\
& Y(t)=L_{0} e^{n t} y(t) ; \\
& K(t)=L_{0} e^{n t} k(t) .
\end{aligned}
$$

The production function (1) can be saved in an intensive form, dividing it by the parties through the effective work units $E>0$ : 


$$
y_{E}(t)=\left(k_{E}(t)\right)^{\alpha}
$$

The equation (11) describes the relation between capital expenditure per unit of effective work $\left(k_{E}\right)$, and production per unit of this work $\left(y_{E}\right)$.

When differentiating capital for the unit of effective work $\left(k_{E}=K / E\right)$ after time $t$ we obtain:

$$
\dot{k}_{E}(t)=\frac{\dot{K}(t) E(t)-K(t) \dot{E}(t)}{(E(t))^{2}}=\frac{\dot{K}(t)}{E(t)}-\frac{\dot{E}(t)}{E(t)} k_{E}(t),
$$

which together with $(2-4)$ gives us:

$$
\dot{k}_{E}(t)=s(t) y_{E}(t)-\mu(t) k_{E}(t),
$$

where: $\mu(t)=\delta+g+l(t)>0$ means the rate of capital loss per unit of effective work. The differential equation (12) is the equivalent of the Solow movement equation in the economic growth model discussed here.

Taking into account the production function in the intense form (11) and the relations (12) and (3), the following differential equation can be obtained:

$$
\dot{k}_{E}(t)=\left(s_{0}+\eta e^{-v \cdot t}\right)\left(k_{E}(t)\right)^{\alpha}-\mu(t) k_{E}(t) .
$$

The equation (13) for each $t \geq 0$ has a trivial solution $\left(k_{E}(t)=0\right)$ and a family of nontrivial integrals ${ }^{2}$.

The equation (13) for $k_{E}>0$ can be written down as:

$$
\left(k_{E}(t)\right)^{-\alpha} \dot{k}_{E}(t)=s_{0}+\eta e^{-v \cdot t}-\mu(t)\left(k_{E}(t)\right)^{1-\alpha} .
$$

By making the following substitution:

$$
q(t)=\left(k_{E}(t)\right)^{1-\alpha} \text {. }
$$

The equation (14) can be reduced to the heterogeneous equation given by the formula:

$$
\frac{\dot{q}(t)}{1-\alpha}=s_{0}+\eta e^{-v \cdot t}-\mu(t) q(t),
$$

which can be transformed into the relations:

$$
\dot{q}(t)=(1-\alpha)\left(s_{0}+\eta e^{-v \cdot t}\right)-(1-\alpha) \mu(t) q(t),
$$

Considering the homogeneous equation from the relation (16) we get:

$$
\dot{q}(t)=-(1-\alpha) \mu(t) q(t),
$$

the solution of equation (17) is given by the formula:

$$
q(t)=A(t) e^{-(1-\alpha)(\delta+g) t}(L(t))^{\alpha-1}
$$

\footnotetext{
2 The trivial integral (as uninteresting from both mathematical and economic point of view) will be further ignored. Non-trivial integral of this equation will determine the time path (or path of growth) of capital for the unit of effective work.
} 
But the factor $\mathrm{A}(t)>0$ is the integral integration constant. Differentiating the equation (18) with respect to time and taking into account the relations (18) we get:

$$
\begin{gathered}
(1-\alpha) s-(1-\alpha)\left(\delta+g+\frac{\dot{L}(t)}{L(t)}\right) A(t) e^{-(1-\alpha)(\delta+g) t}(L(t))^{\alpha-1}= \\
\dot{A}(t) e^{-(1-\alpha)(\delta+g) t}(L(t))^{\alpha-1}+A(t)(\alpha-1)(\delta+g) e^{-(1-\alpha)(\delta+g) t}(L(t))^{\alpha-1}+ \\
A(t) e^{-(1-\alpha)(\delta+g) t}(\alpha-1)(L(t))^{\alpha-2} \dot{L}(t) .
\end{gathered}
$$

Thus, and from the relations (3)-(5) we get 3 :

$$
\begin{gathered}
A(t)=(1-\alpha) s_{0} \int e^{-(1-\alpha)(\delta+g) t} L^{1-\alpha}(t) d t^{2}+(1-\alpha) \eta \int e^{-(1-\alpha)(g+\delta) t} L^{1-\alpha}(t) d t= \\
\frac{(1-\alpha) s_{0}}{2}\left(\frac{\frac{(1-\alpha)}{2}\left(t^{2}(g+\delta)+\ln ^{2}\left(\tau \cdot t+\frac{\theta}{\lambda} e^{-\lambda \cdot t}\right)\right)}{W\left(\frac{1-\alpha}{2 e}\left(\ln ^{2}\left(\tau \cdot t+\frac{\theta}{\lambda} e^{-\lambda \cdot t}\right)+t^{2}((1-\alpha)(g+\delta)-v)\right)\right.}\right)^{2}+ \\
\frac{(1-\alpha) \eta}{2}\left(\frac{\frac{t^{2}}{2}((1-\alpha)(g+\delta)+v)+(1-\alpha) \ln ^{2}\left(\tau \cdot t+\frac{\theta}{\lambda} e^{-\lambda \cdot t}\right)}{W\left(\frac{1-\alpha}{2 e}\left(\ln ^{2}\left(\tau \cdot t+\frac{\theta}{\lambda} e^{-\lambda \cdot t}\right)+t^{2}((1-\alpha)(g+\delta)-v)\right)\right.}\right)^{2}+C .
\end{gathered}
$$

Hence, and from the relations (16) and (19) the capital for the unit of effective work can be written as:

$$
\begin{aligned}
k_{E}(t)= & \frac{e^{-(1-\alpha)(\delta+g) t}}{\left(\tau-\theta e^{-\lambda \cdot t}\right)^{1-\alpha}}\left(\frac{(1-\alpha) s_{0}}{2}\left(\frac{\frac{(1-\alpha)}{2}\left(t^{2}(g+\delta)+\ln ^{2}\left(\tau \cdot t+\frac{\theta}{\lambda} e^{-\lambda \cdot t}\right)\right)}{W\left(\frac{1-\alpha}{2 e}\left(\ln ^{2}\left(\tau \cdot t+\frac{\theta}{\lambda} e^{-\lambda \cdot t}\right)+t^{2}((1-\alpha)(g+\delta)-v)\right)\right)}\right)^{2}+\right. \\
& \left.\frac{(1-\alpha) \eta}{2}\left(\frac{\frac{t^{2}}{2}((1-\alpha)(g+\delta)+v)+\frac{(1-\alpha)}{2} \ln ^{2}\left(\tau \cdot t+\frac{\theta}{\lambda} e^{-\lambda \cdot t}\right)}{W\left(\frac{1-\alpha}{2 e}\left(\ln ^{2}\left(\tau \cdot t+\frac{\theta}{\lambda} e^{-\lambda \cdot t}\right)+t^{2}((1-\alpha)(g+\delta)-v)\right)\right.}+C\right)\right)^{\frac{1}{1-\alpha}} \cdot
\end{aligned}
$$

Assuming that for the discussed problem the Cauchy's boundary condition takes the form $k_{E}(0)=k_{E 0} \geq 0$, the $C$ constant can be written as:

\footnotetext{
${ }^{3} W(x)$ is a special function of W-Lambert (omega function) which is defined as the solution of the following equation (see: Corless, Gonnet, Hare, Jeffrey, \& Knuth, 1996, pp. 329-345).
} 


$$
C=2\left(k_{E 0}\right)^{1-\alpha} \frac{(\tau-\theta)^{1-\alpha}}{1-\alpha}-\left(s_{0}+\eta\right)\left(\frac{(1-\alpha) \ln ^{2}\left(\frac{\theta}{\lambda}\right)}{2 W\left(\frac{1-\alpha}{2 e}\left(\ln ^{2}\left(\frac{\theta}{\lambda}\right)-v\right)\right)}\right),
$$

Hence, and from (20) the integral of equation (14) is given as:

$$
\begin{gathered}
k_{E}(t)=\left[\frac { e ^ { - ( 1 - \alpha ) ( \delta + g ) t } } { ( \tau - \theta e ^ { - \lambda \cdot t } ) ^ { 1 - \alpha } } \left(\frac{(1-\alpha) s_{0}}{2}\left(\frac{\frac{(1-\alpha)}{2}\left(t^{2}(g+\delta)+\ln ^{2}\left(\tau \cdot t+\frac{\theta}{\lambda} e^{-\lambda \cdot t}\right)\right)}{W\left(\frac{1-\alpha}{2 e}\left(\ln ^{2}\left(\tau \cdot t+\frac{\theta}{\lambda} e^{-\lambda \cdot t}\right)+t^{2}((1-\alpha)(g+\delta)-v)\right)\right)}\right)^{2}+\right.\right. \\
\frac{(1-\alpha) \eta}{2}\left(\frac{\frac{t^{2}}{2}((1-\alpha)(g+\delta)+v)+\frac{(1-\alpha)}{2} \ln ^{2}\left(\tau \cdot t+\frac{\theta}{\lambda} e^{-\lambda \cdot t}\right)}{W\left(\frac{1-\alpha}{2 e}\left(\ln ^{2}\left(\tau \cdot t+\frac{\theta}{\lambda} e^{-\lambda \cdot t}\right)+t^{2}((1-\alpha)(g+\delta)-v)\right)\right)}\right) \\
\left.2\left(k_{E 0}\right)^{1-\alpha} \frac{(\tau-\theta)^{1-\alpha}}{1-\alpha}-\left(s_{0}+\eta\right)\left(\frac{(1-\alpha) \ln ^{2}\left(\frac{\theta}{\lambda}\right)}{2 W\left(\frac{1-\alpha}{2 e}\left(\ln ^{2}\left(\frac{\theta}{\lambda}\right)-v\right)\right)}\right)\right)^{1-\alpha}
\end{gathered}
$$

In addition, the product for the unit of effective work is described by the equation:

$$
\begin{gathered}
y_{E}(t)=\left[\frac { e ^ { - ( 1 - \alpha ) ( \delta + g ) t } } { ( \tau - \theta e ^ { - \lambda \cdot t } ) ^ { 1 - \alpha } } \left(\frac{(1-\alpha) s_{0}}{2}\left(\frac{\frac{(1-\alpha)}{2}\left(t^{2}(g+\delta)+\ln ^{2}\left(\tau \cdot t+\frac{\theta}{\lambda} e^{-\lambda \cdot t}\right)\right)}{W\left(\frac{1-\alpha}{2 e}\left(\ln ^{2}\left(\tau \cdot t+\frac{\theta}{\lambda} e^{-\lambda \cdot t}\right)+t^{2}((1-\alpha)(g+\delta)-v)\right)\right)}\right)^{2}+\right.\right. \\
\left.\frac{(1-\alpha) \eta}{2}\left(\frac{\frac{t^{2}}{2}((1-\alpha)(g+\delta)+v)+\frac{(1-\alpha)}{2} \ln ^{2}\left(\tau \cdot t+\frac{\theta}{\lambda} e^{-\lambda \cdot t}\right)}{W\left(\frac{1-\alpha}{2 e}\left(\ln ^{2}\left(\tau \cdot t+\frac{\theta}{\lambda} e^{-\lambda \cdot t}\right)+t^{2}((1-\alpha)(g+\delta)-v)\right)\right.}\right)\right)^{2} . \\
2\left(k_{E 0}\right)^{1-\alpha} \frac{(\tau-\theta)^{1-\alpha}}{1-\alpha}-\left.\left(s_{0}+\eta\right)\left(\frac{(1-\alpha) \ln ^{2}\left(\frac{\theta}{\lambda}\right)}{2 W\left(\frac{1-\alpha}{2 e}\left(\ln ^{2}\left(\frac{\theta}{\lambda}\right)-v\right)\right)}\right)\right|^{\frac{\alpha}{1-\alpha}} .
\end{gathered}
$$




\section{Calibration of model parameters and numerical simulations}

Numerical simulations of the theoretical model presented in point 3 were conducted for the period 2000-2050 and consisted of two stages ${ }^{4}$. In the first stage of numerical simulations the parameters discussed in the third point of the model were calibrated. Calibrations of parameter values started by the determination of parameters related to population growth paths (resulting from the CSO's demographic forecast) and the paths of interest rate investments. When analyzing the data on the evolution of gross investment rates in the Polish economy in 1990-2017 (shown in Figure 1), it can be concluded that:

- investment rates are characterized by high volatility over time,

- an average level of investment rates of the Polish economy in the years 1990-2017 was close to $20 \%$, (exactly $19.9 \%$ ),

- investment rates significantly deviated from the average level both in plus and in minus. The level of economic fluctuations (deviations from the average) was also diversified,

- the highest investment rate was recorded in 1999 and amounted to $24.3 \%$ and the lowest value of this variable was noted in 1993 at the level of $14.9 \%$. This means that the maximum investment rates deviated in plus and minus from the average size by about 5 percentage points.

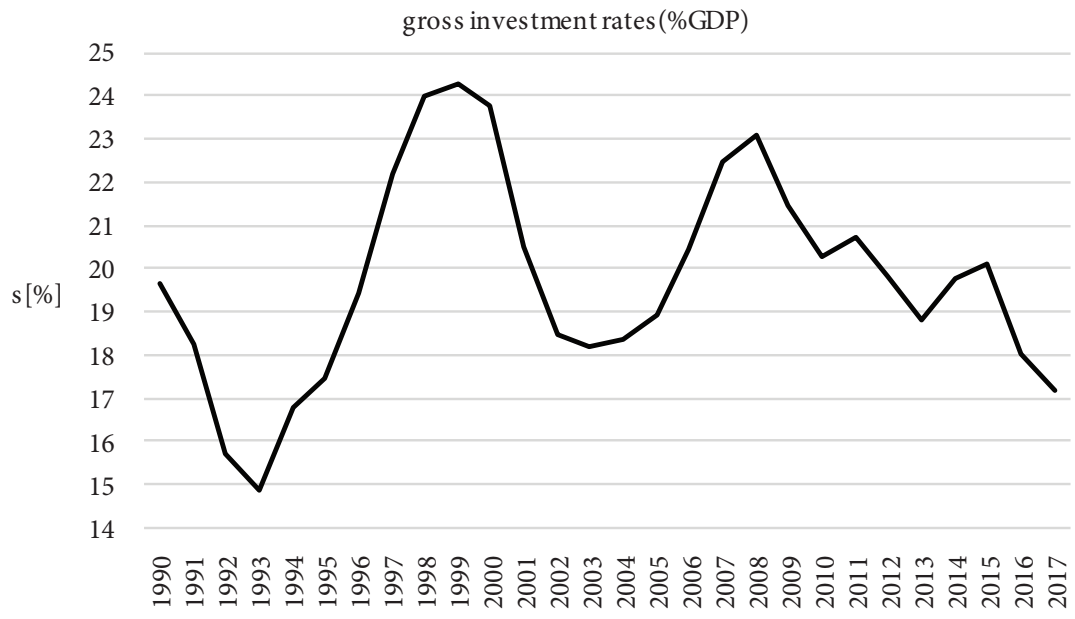

Figure 1. Investment rates in the Polish economy in the years 1990-2017

(source: authors' own study based on the data from UNSTAT)

When smoothing the trajectories of investment rates of the Polish economy, one can observe a growing trend in the years 1990-1999 and a downward trend in the years 2000-2017. The observed trends of changes in investment rates are in the range of $15-25 \%$, which is determined by the maximum deviations from the average investment rates. Therefore, the

\footnotetext{
${ }^{4}$ The choice of the period of 2000-2050 of numerical simulations resulted primarily from the desire to take into account the demographic forecast regarding the population in Poland, whose prediction is made by the Central Statistical Office (CSO) until 2050. From the presented CSO forecasts regarding the size of the population in Poland, it appears that the population in 2000-2050 will be decreasing. CSO predicts that in 2050 population size in Poland will amount to 33.95 million people and will be lower than those recorded in 2000 (38.26 million people) by over 4 million people.
} 
question arises how the trend of shaping investment rates would affect the path of labor productivity growth in the Polish economy.

The assumption 3) shows that in the period $t=0$ the investment rate increase rate reaches the value of $s_{0}+\eta$. More over with $t$ going to infinity, the growth path of investment rates tends asymptotically to the value of $s_{0}$. The above properties allow you to place the following boundary conditions:

$$
s_{0}+\eta=s_{2000} \wedge s_{0}=s_{2050},
$$

where $s_{2000}$ means the investment rate in Poland in 2000, and $s_{2050}$ it is the projected rate of investment in the Polish economy in 2050. In addition, depending on the parameter $\eta$, the growth path of the investment rate can be both a rising and decreasing function with respect to time. This allowed the adoption of two scenarios regarding the investment rates.

In the next stage two variants of the investment rates in Poland in the years 2000-2050 were adopted:

- Variant I, investment rates decrease exponentially from 25 to 15\%.

- Variant II, investment rates grow exponentially from 15 to $25 \%$.

The above variants of investment interest rates are presented in Figure $2^{5}$.

$s(0.25 \rightarrow 0.15)$

0.3

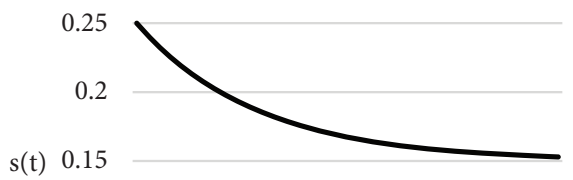

0.1

0.05

0

$\begin{array}{lllllllllll}0 & 5 & 10 & 15 & 20 & 25 & 30 & 35 & 40 & 45 & 50\end{array}$

in years $s(0.15 \rightarrow 0.25)$

$$
0.3
$$

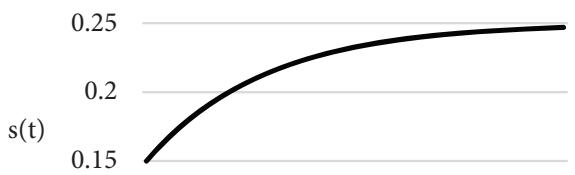

0.1

0.05

0

$\begin{array}{lllllllllll}0 & 5 & 10 & 15 & 20 & 25 & 30 & 35 & 40 & 45 & 50\end{array}$

in years

Figure 2. Trajectories of investment rates in the analyzed variants (source: authors' own calculations)

The analytical form of the growth path of the number of employees was presented in the assumption of 4). In the period $t=0$, the number of employees is $\tau-\theta$ which in the discussed time horizon corresponds to the period of 2000, while at $t$ to infinity, the path smoothes asymptotically to the constant asymptote $\tau$. This allows you to accept the following boundary conditions:

$$
\tau-\theta=L_{2000} \wedge \tau=L_{2050}
$$

\footnotetext{
5 Obviously, in both options actual investment rates are subject to economic fluctuations and in Figure 2 there are presented smoothed trajectories of an increase or a decrease of investment rates taken into account during numerical simulations.
} 
Where $L_{2000}$ is the number of employees in Poland in 2000 published by the Central Statistical Office, and $L_{2050}$ means the population of the forecast number of employees in 2050 . In order to determine the forecast values $L_{2050}$, the authors used the economic activity ratio (the relation of employees to the population). Assuming various scenarios concerning shaping of the economic activity coefficient and then weighing it with the forecast population in 2050 , the forecast value of the number of employees in 2050 was received.

Similarly as in the case of investment rates, changes in the economic activity coefficient were also considered in two variants (Dykas, Mentel, \& Misiak, 2018):

Variant I (realistic) where, according to the Central Statistical Office's forecast regarding population size development in Poland until 2050, it was assumed that the population from 38.26 million people (in 2000) declined exponentially to 33.95 million people (in 2050 r.). On the other hand, the economic activity coefficient is growing exponentially from 0.38 , which was recorded in the Polish economy in 2000 to 0.5 in 2050. The adoption of such a level of coefficient in 2050 resulted from Poland's achieving an average level that characterized the economies with the highest level of this ratio among EU economies in 2016, namely: British, Dutch, German and Swedish.

Variant II (optimistic) where the assumptions regarding population size are identical to variant I, whereas in the case of the ratio it was assumed that by 2050 its increase would be $50 \%$ higher than in variant I and in 2050 it would reach 0.56 .

In the present analyzes, numerical simulations were dropped based on the assumption of declining economic activity coefficients. First of all, in the Polish economy this coefficient is one of the lowest in the entire EU, so a further drop would be contrary to the idea of real convergence to the more developed EU15 economies. Thus, if the real convergence processes are also taking place in the matter of the involvement of a larger part of society in economic activity (convergence of labor markets), it is natural to adopt increasing economic activity rates in the analyzed period. Secondly, in the majority of EU countries, this coefficient is definitely higher than in Poland, which may mean that despite the structural differences among economies, there is the possibility of increasing this coefficient, as indicated by the analysis of statistical data from countries such as the United Kingdom, the Netherlands, Germany or Sweden.

The adoption of the above assumptions as to the size of the population and the economic activity coefficient according to the relation (4) considered in the model work determines the growth paths of the employed in the considered variants, which is summarized in Figure 3.

When analyzing the trajectories of the number of people working in the Polish economy over the time horizon (Figure 3), it is worth noting that despite the population decline resulting from the demographic projection, the number of the employed increases and reaches about 17 million people (variant I) and about 19 million people (variant II). These increases in employment result primarily from the assumptions of the growing economic activity rate from 0.38 in 2000 to 0.5 and 0.56 in 2050. The number of the employed in 2050 in variant II will be higher by about 2 million employees than in variant I. It turns out that despite the pessimistic CSO forecasts regarding population decline, this does not necessarily have a negative impact on the number of employees. The number of employees depends not only on the demographic situation but, to a large extent, it is an effect of shaping the labor market 

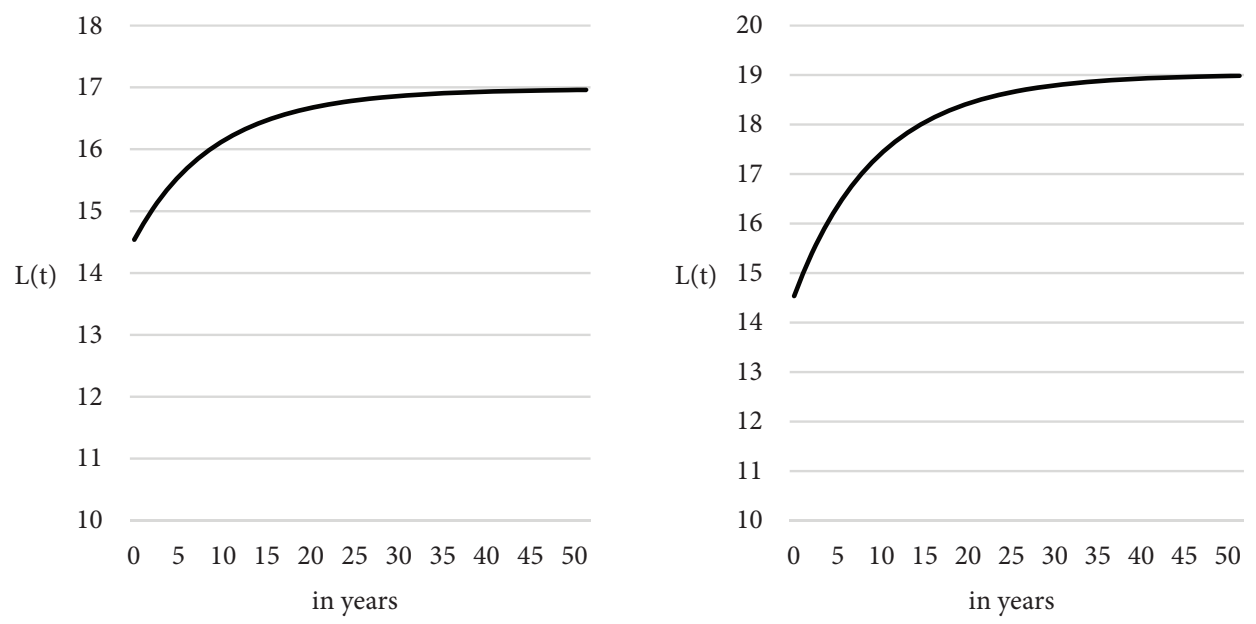

Figure 3. Trajectories of employees L(t)in the adopted variants: (from left) variant I and variant II, respectively (source: authors' own calculations based on CSO data (www.stat.gov.pl)

processes. The changes in the labor market may be internal as well as external. The internal changes in the labor market result from such processes as: a drop in the unemployment rate, voluntary or statutory extension of the working age (retirement age), and higher professional activity, e.g. among women or young people. All the above factors as well as the relatively low share of those employed in the population in Poland, in comparison to other European economies, determine significantly the fact that in the considered variants an increasing level of economic activity coefficient was adopted. External changes in the labor market may be the result of, above all, migration processes. However, due to the lack of reliable data on the balance of labor migration until 2050, this aspect is not included in the analyzed model. However, it is worth emphasizing that migration processes have a significant impact on the number of employees. If the balance of labor migration Poland was positive, it would mean an increase in the number of people working in the Polish economy. A negative balance of labor migration would have a negative impact and would mean a decrease in the number of employees.

Moreover, in an expert manner, arbitrarily based on the review of literature, the rate of capital depreciation at the level of $5 \%(\delta=0.05)$, the rate of technical progress at the level of $2 \%(g=0.02)$ and flexibility of production with respect to capital at the level of $\alpha=0.33$ were adopted 0.33 .

Based on the calibrated parameters of the trajectory of changes in investment rates, the economic activity coefficient and the variants adopted in the considerations, numerical simulations of the analyzed model were made. The results of numerical analysis of product growth paths per effective unit of work $\left(y_{E}(t)\right)$ are presented in Table 1 and in Figures 4-5.

When analyzing the data summarized in Table 1 and in Figure 4 it can be observed that in each of the considered variants of changes in both investment rates and economic activity coefficients, the product per unit of effective work $\left(y_{E}(t)\right)$ is characterized by a growing tendency. However, the range of these increases is diversified. 
Table 1. Results of numerical simulations of the product per unit of effective work $\left(y_{E}(t)\right)$ in the analyzed variants of investment interest rates $(s)$ and the economic activity ratio (source: authors' own calculations)

\begin{tabular}{|c|c|c|c|c|}
\hline \multirow{2}{*}{$\begin{array}{c}\text { Simulation } \\
\text { period (in } \\
\text { years) }\end{array}$} & \multicolumn{4}{|c|}{ Changes in the economic activity coefficient } \\
\cline { 2 - 5 } & \multicolumn{2}{|c|}{ Economic activity coefficient $\rightarrow 0.5$} & \multicolumn{2}{c|}{ Economic activity coefficient $\rightarrow 0.56$} \\
\cline { 2 - 5 } & $\mathrm{s}(0.15 \rightarrow 0.25)$ & $\mathrm{s}(0.25 \rightarrow 0.15)$ & $\mathrm{s}(0.15 \rightarrow 0.25)$ & $\mathrm{s}(0.25 \rightarrow 0.15)$ \\
\hline 0 & 1 & 1 & 1 & 1 \\
\hline 10 & 1.357 & 1.443 & 1.419 & 1.510 \\
\hline 20 & 1.678 & 1.657 & 1.779 & 1.780 \\
\hline 30 & 1.875 & 1.773 & 2.052 & 1.937 \\
\hline 40 & 2.035 & 1.839 & 2.252 & 2.031 \\
\hline 50 & 2.150 & 1.878 & 2.395 & 2.089 \\
\hline
\end{tabular}

The highest product increments $y_{E}(t)$ were characterized by combinations when the economic activity coefficient increased to 0.56 while investments increased from 15 to $25 \%$. Then, during the simulation period, the product $y_{E}(t)$ increases 2.4 times in relation to its initial value, which for 2000 was normalized to unity. The lowest increase in $y_{E}(t)$ was recorded for the realistic variant in terms of the economic activity rate (when $\rightarrow 0.5$ ) and when investment rates in the analyzed period drop from 25 to $15 \%$. With such a combination of changes in both the economic activity rate and the investment rates, the product $y_{E}(t)$ would increase by 1.9 times. Interestingly, with combinations of variants, when the economic activity coefficient $\rightarrow 0.5$ and $s$ increases from 15 to $25 \%$ and when this ratio $\rightarrow 0.56$ but investments fell from 25 to $15 \%$, an increase of product $y_{E}(t)$ in the assumed simulation period was at a similar level (in both cases approx. 2.1 times higher than initially). Thus, if

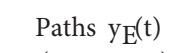

at $s(0.25 \rightarrow 0.15)$

\section{5}

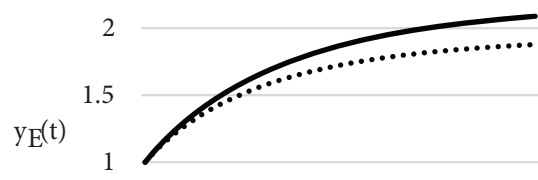

0.5

0

$\begin{array}{lllllllllll}0 & 5 & 10 & 15 & 20 & 25 & 30 & 35 & 40 & 45 & 50\end{array}$

in years

coeff. $=0.5 \longrightarrow$ coeff. $=0.565$
Paths $\mathrm{y}_{\mathrm{E}}(\mathrm{t})$

at $s(0.15 \rightarrow 0.25)$

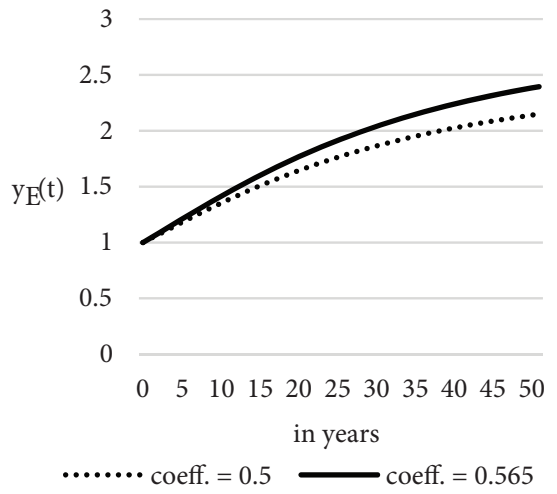

Figure 4. Trajectories of product growth per unit of effective work $(v E(t))$ (source: authors' own calculations) 
Paths $\mathrm{yE}_{\mathrm{E}}(\mathrm{t})$

at coeff. $\rightarrow 0.5$

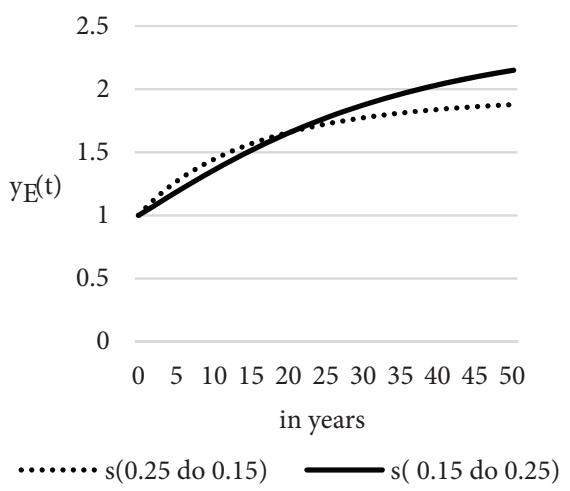

Paths $\mathrm{yE}_{\mathrm{E}}(\mathrm{t})$

at coeff. $\rightarrow 0.56$

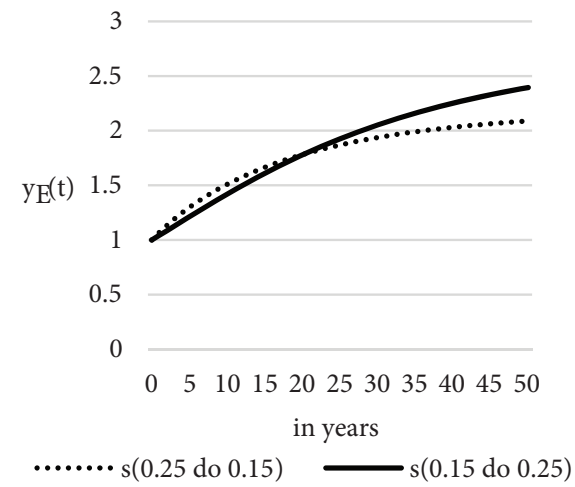

Figure 5. Product growth trajectories per unit of effective work $\left(v_{E}(t)\right)$ when the economic activity coefficient reaches 0.5 (left side) or reaches the level of 0.56 (right side)

(source: authors' own calculations)

the Polish economy failed to achieve an optimistic variant of changes in economic activity $(\rightarrow 0.56)$ only the realistic option $(\rightarrow 0.5)$, then it is possible to achieve the same or similar level of $y_{E}(t)$, but this requires a growing trend of investment rates from 15 to $25 \%$. Therefore, an important role here plays the effect of work substitution by increasing capital expenditure on physical capital.

Considering the tendencies of changes in investment rates with the same levels of economic activity coefficient (Figure 5), it can be noticed that regardless of the trends of investment rates, the product $y_{E}(t)$ is characterized by a growing trend.

However, the comparison of growth paths $y_{E}(t)$ with the same $\tau$ but different tendencies of changes in investment rates is characterized by the fact that in the first half of the simulation period the path $y_{E}(t)$ is higher when investments are characterized by a downward trend $(\mathrm{s}(0.25 \rightarrow 0.15))$. In the second half of the simulation period, the path is higher when the investments grow from 15 to $25 \%$. Such a change in the position of the $y_{E}(t)$ paths results from different trends in investment interest rates. In principle, changes in the position of paths due to the trends in changes in investment rates result from the level of investment rates at a given point in the simulation period. These conclusions coincide with the analysis of the impact of investment rates, for example in the Solow model, which shows that the higher the investment rate, the higher the path of product growth per unit of effective work. The above dependencies take place when both the realistic and the optimistic variants of changes in the economic activity coefficient are considered.

\section{Conclusions}

Based on numerical simulations of the analyzed model, it appears that negative demographic forecasts for Poland do not have to affect economic growth negatively. This is due to the fact that, first of all, the Polish economy has one of the lowest shares working to the size 
of the population among the European Union countries. This means that there is a part of the population (working gap) that could be but is not counted as a working resource. As examples of countries such as Germany, Sweden, the United Kingdom or the Netherlands indicate (where the average percentage of workers in relation to the population in 2016 was about 12 percentage points higher than in Poland), there are some opportunities to involve the greater part of society in production processes. In the case of the Polish economy, the activities consisting in increasing the shares of people working in the population (i.e. the growing economic activity rate) with negative demographic projections may be amortizing. This means that if this ratio remained stable with a simultaneous decline in the population, the number of employed persons would also decrease, which would have a negative impact on an economic growth. When the population decline is accompanied by a growing percentage of employees to the population, the working population in the economy may remain unchanged. Then an increase in the economic activity coefficient will amortize the population decline. In the case when the rate of increase in the economic activity coefficient is higher than the rate of decline in the population, then the working people in the economy grows. However, it should be noted that such dependencies are possible in economies with a low share of working population (which is exemplified by Poland) since in such economies there are real possibilities to increase the economic activity ratio. In addition, the economy must be characterized by an appropriate age pyramid which allows an increase in the share of people working in relation to the population by eliminating certain inefficiencies of the labor market, i.e.: high unemployment rate, poor activation of women and young people in the labor market, and flexibility of the retirement age.

Secondly, as demonstrated by the carried out analyzes, there are possibilities to substitute human labor, but this requires growing investment rates. Such a relationship suggests that in a situation of population decline, the stimulated investment policy may play an important role.

In summary, it can be stated that in the situation of an economy where a decline in population size is forecasted, negative effects of the impact on economic growth can be avoided. However, it requires the involvement of a larger part of the population in economic activity (growing economic activity rate) by eliminating labor market disabilities (reducing unemployment, greater women's activation, voluntary extension of the retirement age) which may constitute recommendations for a properly conducted labor market policy. In addition, the analysis conducted for Poland shows that even if the further increase in the economic coefficient would be impossible, similar effects of labor productivity growth can be achieved through rising investment rates in the economy. Therefore, it can be an appropriate recommendation for pro-investment economic policy.

Based on the analyzes conducted, some limitations and future possibilities of conducting further research may be indicated. It is worth noting that the number of people working in economy is influenced not only by internal conditions (such as: a demographic growth, a level of economic activity rate, an unemployment rate or age of retirement). Nowadays, the migration processes are also important. These external inflows or outflows of employees can significantly affect the total number of employees in a given economy, which may depreciate or deepen the effects of negative demographic changes. The lack of consideration of migra- 
tion is a certain limitation of the approach presented in the article, but it can be the basis for further research.

In addition, the article is based on a semi-endogenic model, repealing the assumptions about the exogenous growth path of the number of employees and fixed investment rates. It is possible to base the modeling of labor productivity growth on a purely endogenous growth model and compare the obtained simulation results with the results presented in this article.

\section{References}

Aghion, P., \& Howitt, P. (1992). A model of growth through creative destruction. Econometrica, 60, 323-351. https://doi.org/10.2307/2951599

Barro, R. (1989). A cross-country study of growth, saving and government. Working Paper No. 2855, NBER. https://doi.org/10.3386/w2855

Barro, R. (1991). Economic growth in a cross section of countries. Quarterly Journal of Economics, 106, 407-443. https://doi.org/10.2307/2937943

Barro, R. J., \& Sala-i-Martin, X. (2004). Economic growth. Cambridge, MA: MIT Press.

Barro, R. J. (1997). Determinants of economic growth: A cross-country empirical study. Cambridge, MA: MIT Press. https://doi.org/10.3386/w5698

Baumol, W. J. (1990). Entrepreneurship. Productive, unproductive and destructive. Journal of Political Economy, 98(5), 893-921. https://doi.org/10.1086/261712

Becker, G. S., Murphy, K., \& Tamura, R. (1990). Human capital fertility and economic growth. Journal of Political Economy, 98(5), 12-37. https://doi.org/10.1086/261723

Bianca, C., \& Guerrini, L. (2014). Existence of limit cycles in the Solow model with delayed-logistic population growth. Scientific World Journal, 2014(4), 1-8. https://doi.org/10.1155/2014/207806

Botrić, V., Božić, Lj., \& Broz, T. (2017). Explaining firm-level total factor productivity in post-transition: manufacturing vs. services sector. Journal of International Studies, 10(3), 77-90. https://doi.org/10.14254/2071-8330.2017/10-3/6

Brida, J. G., \& Accinelli, E. (2007). The Ramsey model with logistic population growth. Economics Bulletin, 3(15), 1-8.

Bucci, A., \& Guerrini, L. (2009). Transitional dynamics in the Solow-Swan growth model with AK technology and logistic population change. The B.A. Journal of Macroeconomics, 9, 1-17. https://doi.org/10.2202/1935-1690.1954

Cobb, C. W., \& Douglas, P. H. (1928). A theory of production. American Economic Review, 18.

Corless, R. M., Gonnet, G. H., Hare, D. E. G., Jeffrey, D. J., \& Knuth, D. E. (1996). On the Lambert W function (PostScript). Advances in Computational Mathematics, 5, 329-359. https://doi.org/10.1007/BF02124750

Dykas, P., \& Misiak, T. (2016). Neoklasyczny model wzrostu gospodarczego z sinusoidalnymi inwestycjami. Przeglad Statystyczny, 63(1), 49-65.

Dykas, P., Mentel, G., \& Misiak, T. (2018). The neoclassical model of economic growth and its ability to account for demographic forecast. Transformations in Business \& Economics, 17, No 2B (44B), 684-700.

Ferrara, M., \& Guerrini, L. (2009). The Ramsey model with logistic population growth rate and Benthamite Felicity function revisited. WSEAS Transaction on Mathematics, 8, 97-106.

Filipowicz, K., Misiak, T., \& Tokarski, T. (2016). Bipolar growth model with investment flows. Economics and Business Review, 2(16) 3, 32-56. https://doi.org/10.18559/ebr.2016.3.4 
Filipowicz, K., Syrek, R., \& Tokarski, T. (2017). Ścieżki wzrostu w modelu Solowa przy alternatywnych trajektoriach liczby pracujących. Przegląd Statystyczny, 64, 21-40. https://doi.org/10.18778/0208-6018.326.12

Galor, O., \& Weil, D. N. (2000). Population, technology and growth. From Malthusian stagnation to demographics. American Economic Review, 90(4), 806-828. https://doi.org/10.1257/aer.90.4.806

Galor, O. (2011). Unified growth theory. Princeton University Press, Princeton \& Oxford. https://doi.org/10.2307/j.ctvcm4h7m

Grossman, G. M., \& Helpman, E. (1991). Innovation and growth in the global economy. MIT Press, Cambridge.

Guerrini, L. (2006). The Solow-Swan model with the bounded population growth rate. Journal of Mathematical Economics, 42, 14-21. https://doi.org/10.1016/j.jmateco.2005.05.001

Guerrini, L. (2010a). A closed form solution to the Ramsey model with logistic population growth. Economic Modelling, 27, 1178-1182. https://doi.org/10.1016/j.econmod.2010.03.002

Guerrini, L. (2010b). Logistic population change and the Mankiw-Romer-Weil model. Applied Sciences, 12, 96-101.

Jones, C. I. (1995). R\&D-based models of economic growth. Journal of Political Economy, 103(4), 759783. https://doi.org/10.1086/262002

Kudinova, A., \& Verba, D. (2014). Modern transformation of relations between production and consumption. Economics \& Sociology, 7(2), 34-46. https://doi.org/10.14254/2071-789X.2014/7-2/4

Lucas, R. E. (1988). On the mechanics of economic development. Journal of Monetary Economics, 22(1), 4-42. https://doi.org/10.1016/0304-3932(88)90168-7

Malaga, K. (2011). The main strands and dilemmas of contemporary economic growth theory. Argumenta Oeconomica, 1(26), 17-42.

Mankiw, N. G., Romer, D., \& Weil, D. N. (1992). A contribution to the empirics of economic growth. Quarterly Journal of Economics, 107(2), 407-437. https://doi.org/10.2307/2118477

McCombie, J. S. L. (2000). The Solow residual, technical change and aggregate production functions. Journal of Post Keynesian Economics, 23(2), 267-297. https://doi.org/10.1080/01603477.2000.11490280

McCombie, J. S. L. (2001). What does the aggregate production function tell us? Second thoughts on Solow's, second thoughts on growth theory. Journal of Post Keynesian Economics, 23(4), 589-615. https://doi.org/10.1080/01603477.2001.11490301

Prettner, K. (2013). Population aging and endogenous economic growth. Journal of Population Economic, 26, 811-834. https://doi.org/10.1007/s00148-012-0441-9

Romer, D. (2001). Advanced macroeconomics (2nd ed.), chapters 1-3. Boston: McGraw-Hill, Mass.

Romer, P. M. (1986). Increasing returns and long-run growth. Journal of Political Economy, 94, 10021037. https://doi.org/10.1086/261420

Romer, P. M. (1990). Endogenous technological change. Journal of Political Economy, 98, 71-102. https://doi.org/10.1086/261725

Solow, R. M. (1956). A contribution to the theory of economic growth. Quarterly Journal of Economics, February. https://doi.org/10.2307/1884513

Żółtowska, E. (1997). Funkcja produkcji. Teoria, estymacja, zastosowania. Łódź: Wydawnictwo Uniwersytetu Łódzkiego. 